\title{
Research on the voltage of Hybrid Energy Storage System in Charging Electric Vehicles
}

\author{
Kai LI ${ }^{1, a^{*}}$, Xiang-Qun CHEN ${ }^{1}$ Jing-Bo LI ${ }^{1}$ He-Qing ZENG ${ }^{1}$ Lei YANG ${ }^{2}$ \\ ${ }^{1}$ State Grid Hunan Electric Power Company Metrology Center, Changsha, China \\ ${ }^{2}$ Beijing Puri High-voltage Transmission Technology Co, Ltd of State Grid, Beijing, China \\ a18338567@qq.com \\ ${ }^{*}$ Corresponding author
}

Keywords: hybrid energy storage system, integrated magnetic structure, power quality, electric vehicles, DC-DC converter.

\begin{abstract}
Integrated Magnetic structure can reduce the overall size and weight of a converter, decrease the core losses of a converter. In this paper, the aim of studying the magnetic integration technology applied to DC-DC converters of electric vehicles, is to gain further loss reduction and improve the life of an electric car battery, etc.. At the same time, adding a second-order Bessel low pass filter with integrated magnetic structure will improve filter performance and optimize the power quality of the hybrid energy storage system. Combined battery and ultra capacitor hybrid energy storage systems consist of high-capacity storage, fast response process, recovery of braking energy, which can extend the life of the electric vehicle and ensure a rapid increase in the speed requirements. The good performance of the hybrid energy storage system in a typical driving cycle has been verified by MATLAB Simulation and experimental tests.
\end{abstract}

\section{Introduction}

The Electric Car Era is coming. In order to make electric vehicles the same as fuel vehicles, they need have a fast transient acceleration energy, long-distance endurance and light-weight multiple storage devices. In a hybrid energy storage system, battery and super capacitor match well, which has been proven by actual batteries,[1-2] such as lithium batteries. With high energy density, Lithium batteries can provide long distance endurance for electric vehicles, while the super capacitor has a feature of fast response and a maximum instantaneous output current that can help electric vehicle with its accelerating performance, which is comparable to a traditional car, sometimes even better. An optimizing energy storage device is a subject in improving the performance of electric vehicles. It is necessary to increase the capacity of the battery and reduce the size and weight of the battery to increase the charging rate. Reducing body weight itself improves the life of electric vehicles and reduces losses.

As important power electronic devices, DC-DC converters have been developed over the years. The integrated magnetic structure of DC-DC converter, as the connection of energy storage system, the grid and the essential part of the DC motor, which is simpler and more efficient, can significantly reduce the volume and weight of the converter. ${ }^{[3-9]}$ In this paper, the proposed DC-DC converter has specific topology and operating modes, as well as the battery and the super capacitor. Finally, simulation and experimental analysis shows that the performance of the hybrid energy storage system is in line with the theoretical analysis.

\section{Hybrid energy storage system}

Figure 1 is a hybrid energy storage system consists of DC/DC converters, super capacitors and a battery pack. DC/DC converters consist of four IGBT switches T1-T4 and their corresponding diodes (added battery) tube D1-D4, an integrated magnetic structure-self-inductance L1, L2 and mutual-inductance $\mathrm{M}$, which share a core inductor. The battery pack provides power for the smooth DC motor, which is a major energy electric vehicle. The super capacitor is used to improve the instantaneous state of peak power supply. The power management system according to the load demand determines the electrical energy flow. 
The converter has five main operating modes :( The modes change along with the additional battery pack.)

(1)Working mode one, Buck mode through the AC/DC converter charge the battery and super capacitor from AC power supply (grid). This mode is used to charge a vehicle in a parking lot.Power from the AC power supply transfer through the AC/DC converter to DC, by T3, D4, L1(consist of buck converters) - charge the battery; byT1, D2, L2 - charge the super capacitor.

(2)Working mode two, under the boost mode, the battery energy transmit to the DC motor side, By L1, T4, D3 - consisting of the boost converter - delivering power to the DC motor side.

(3)Working mode three, the super-capacitor power under boost mode delivered to the DC side, is used to improve the acceleration conditions for electric vehicles. L2, T2, D1, consist of boost converters, deliver power to the DC motor side.

(4)Working mode four,the buck mode from DC motor side, recycle braking energy which stores in the super capacitor. This mode is the same as mode 1 .

(5)Working mode five, under the boost modes, where battery electric energy is transmitted to the super capacitor when the super capacitor SOC (State of Charge) is reduced to the lowest limit standard. In this case, the battery pack provides power to the DC motor side and the super capacitor obtains DC power from the charging side.

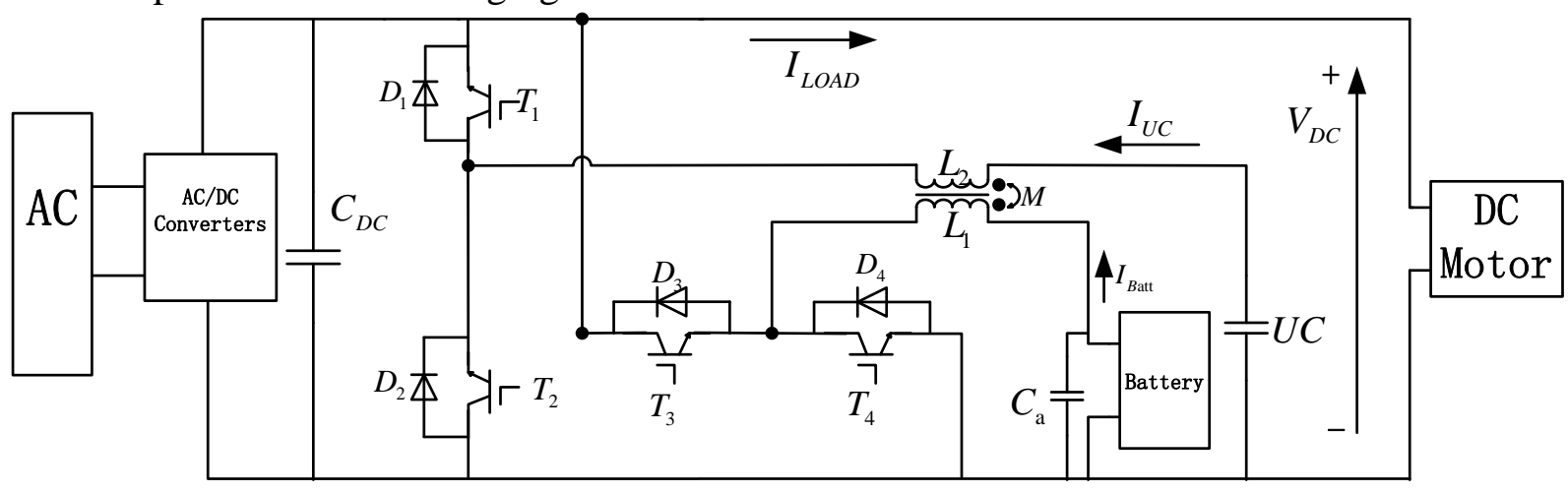

Fig.1 Topology of the hybrid energy storage system

Table 1 shows the specific operation mode of hybrid energy storage system corresponding energy flows and the corresponding operating mode DC-DC converter.

Tab. 1 The operation mode of hybrid energy storage system

\begin{tabular}{|c|c|c|c|}
\hline Working mode & Power source & Power flow & Operation mode \\
\hline $\begin{array}{c}\text { One } \\
\text { Or four }\end{array}$ & $\begin{array}{c}\text { AC power Or braking } \\
\text { energy }\end{array}$ & Battery and super capacitor & Buck \\
\hline Two & Battery & DC & Boost \\
\hline Three & $\begin{array}{c}\text { Super } \\
\text { Capacitor }\end{array}$ & DC motor & Boost \\
\hline Five & Battery & $\begin{array}{c}\text { Super capacitors and DC } \\
\text { motors }\end{array}$ & Boost or buck \\
\hline
\end{tabular}

\section{Based on the DC/DC converter with integrated magnetic structure}

Magnetic elements, such as inductors, are the main components of energy conversion, filters, electrical isolation, and energy storage. The size of the magnetic element is a major factor in determining the size and weight of an inverter. To achieve integration of a plurality of magnetic elements, a core should be equipped with a plurality of magnetic circuits. With multiple 
characteristics of the magnetic circuits, E-type core is useful in this aera. Different discrete magnetic elements integrated in multiple alternate fluxes much simpler. In this paper, the use of the inductance of the inductor is integrated, i.e., a coupled inductor. As shown in Figure 1,L1 as the output filter inductor, $\mathrm{L} 1$ as the external inductor, and $\mathrm{Ca}$ as additional capacitance. In the steady state, without regard to the capacitor voltage ripple, The voltage $\mathrm{Ca}$ is equal to the output voltage of L2 and L1 meet the conditions on the ratio of voltage, by integrating the inductance can reduce the output current ripple,in Section 4 of simulation and experimental analysis, it can be seen specifically that the effect on the structure of the integrated magnetic's filter out the ripple.

Tab.2 Comparsion of the integrated magnetic structure with discrete inductors

\begin{tabular}{cccc}
\hline Feature & $\begin{array}{c}\text { Two discrete } \\
\text { inductors }\end{array}$ & $\begin{array}{c}\text { Integrated magnetic } \\
\text { structure }\end{array}$ & Effect \\
Surface area & $79.15 \mathrm{~cm}^{2}$ & $60 \mathrm{~cm}^{2}$ & $\sim 24.2 \%$ \\
Core volume & $104.19 \mathrm{~cm}^{3}$ & $79.60 \mathrm{~cm}^{3}$ & $\sim 23.60 \%$ \\
Core weight & $0.31 \mathrm{~kg}$ & $0.23 \mathrm{~kg}$ & $\sim 25.8 \%$ \\
Wire weight & $0.21 \mathrm{~kg}$ & $0.21 \mathrm{~kg}$ & $0 \%$ \\
Reduce costs & & & $\sim 23.6 \%$ \\
\hline
\end{tabular}

As is shown in Table 2, using magnetic integrated structure compared with two discrete inductors, the volume and weight of magnetic components have been significantly reduced, and in the electric vehicle application, the effect is more pronounced, and it can reduce the overall size and weight of the energy storage system and equivalent to reducing the weight of the entire body,increases the body as a whole can accommodate space.

\section{Simulation and Experimental Analysis}

Simulation analysis of this hybrid energy storage system is applied to a typical car driving cycle to test the dynamic performance of the system . Simulation models use MATLAB Simulink, SimPower Systems, Control System and Toolbox. The detailed data of the simulation systems are presented in Table 3.

The simulation will simulate cars during the acceleration, constant speed driving, braking and other behaviours as stability and the voltage of the load side, the battery, ripples of super capacitor current. Finally, experiments on the load side will observe how the current of the super capacitor and the battery pack changes. 
Tab.3 Simulation system specification

\begin{tabular}{cc}
\hline \multicolumn{1}{c}{ Detailed simulation parameters } \\
\hline DC side voltage & $V_{D C-\text { nom }}=300 \mathrm{~V}$ \\
$V_{\text {batt }- \text { nom }}=144 \mathrm{~V}$ & $4400 \mu \mathrm{F}$ \\
Rated voltage of the battery pack & $V_{U C-n o m}=125 \mathrm{~V}$ \\
$C_{D C}$ & $10.12 \mathrm{mH}$ \\
Rated voltage of the super capacitor & $580 \mu \mathrm{H}$ \\
$L_{1}$ & $580 \mu \mathrm{H}$ \\
$L_{2}$ & $f_{s}=15 \mathrm{kHz}$ \\
$M$ & $T_{s t}=5 \mu \mathrm{s}$ \\
Switching frequency
\end{tabular}
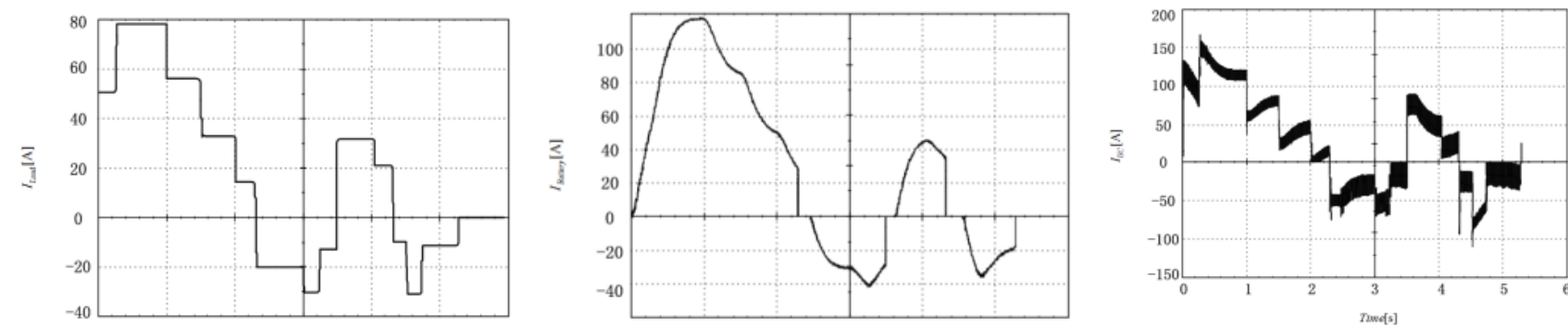

Fig.2 Load current, battery and the Ultracapacitor current variation diagram in a standard simulation cycle

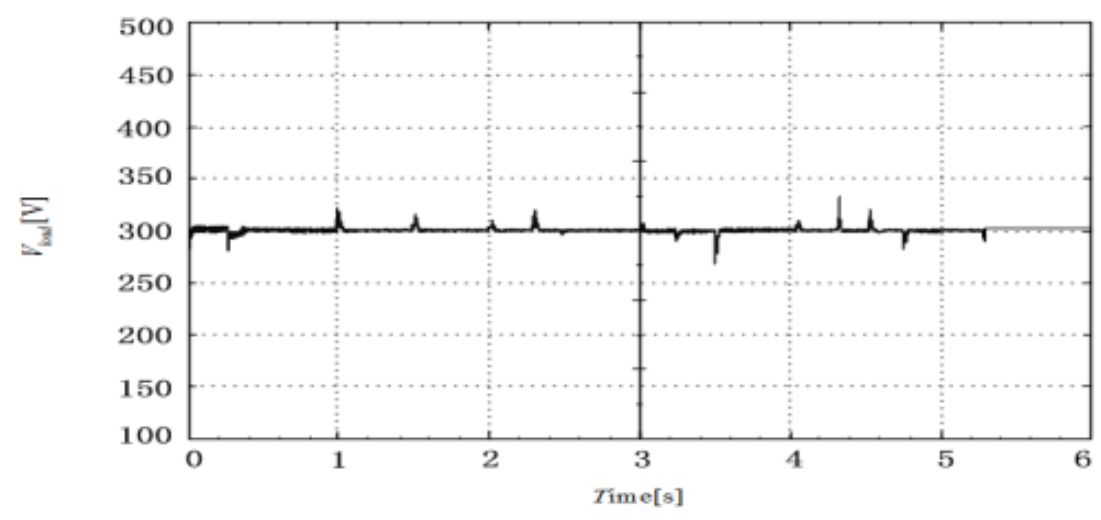

Fig.3 DC motor side ( load side ) voltage

As is shown in Figure 2, the load current corresponds to the conventional driving cycle is very smooth, almost no ripples. Compared with the super capacitor current, battery current changes much smoother without instantaneous mutation. Output current of the battery pack is smooth with just a few ripples, which will not only extend the life of the battery pack, but also reduce the loss of current ripples. When the mutation is buffering, abrupt changes of great current is normal. At the same time, you can notice the difference between the load, the battery and the super capacitor, which is caused by different energy storage device and the terminal voltage of the load. As is shown in Figure 3, side voltage of the load is almost stable. Small amount of fluctuations is due to the instantaneous rise or fall of the voltage, which makes the vehicle accelerate or brake. The voltage of the super capacitor can be quickly restored to $300 \mathrm{~V}$. 


\section{Conclusions}

The integrated magnetic structure of the new bi-directional converter has improved input power quality in electric vehicles and electric drive equipments, which makes the DC motor stabler and more efficient. Compared to traditional hybrid energy storage system, this system has significantly reduced its volume, weight and the influence caused by the ripples of the DC motor. Its excellent performance has been proved by simulation tests and experimental analysis .

\section{Acknowledgements}

This work was supported by STATE GRID Corporation of China research project-Research on the field test and operation evaluation technology of electric vehicle charging equipment.

\section{References}

[1] Petar J. Grbovi', Philippe Le Moigne. A three-terminal ultracapacitor-based energy storage and PFC device for regenerative controlled electric drives[J]. IEEE transactions on industrial electronics.2012.6:301-310.

[2] Z. Li, O. Onar, and A. Khaligh. Power management, design, and simulations of a battery/ultracapacitor hybrid system for small electric vehicles[J]. Soc. Automotive Eng. (SAE) World Congr.Detroit, MI, Apr. 2009.

[3] CHEN Qian-hong, Ruan Xin-bo, Yan Yang-guang. The application of the magneticintegration techniques in switching power supply[J].Transactions of China Electrotechnical Society, 2004, 19(3):1-7.

[4] LIU Xue-chao, ZHANG Bo, QIU Dong-yuan. Modeling of multiphase parallel magnetic integrated circuit voltage regulator module[J]. Chinese Society for Electrical Engineering, 2006, 16(19):145-151.

[5] QIAO Lei, LIU Yong-qiang. Integrated magnetic technology and its application in power electronic[J]. Pr- oceedings of the CSU - EPSA, 2005, 17(3):34-38.

[6] WANG Hua-feng, CHEN Ming, XU De-hong. Application of shunt active power filter with integrated magnetics[J]. Electrical Applications, 2006, 25(12):80-84.

[7] CAI Xuan-san, GONG Shao-wen. High frequency power electronics[M].Beijing: Science Press, 1993:100-156.

[8] O. Onar and A. Khaligh. Dynamic modeling and control of a cascaded active battery/ultracapacitor based vehicular power system[J]. Proc.Veh Power Propulsion Conf. (VPPC), Harbin, $2008,: 1-4$.

[9] YANG Yu-gang. Magnetic technology of modern power electronics[M]. Beijing: Science Press, 2003: 54-79. 